\title{
Optimisation of Mould Design for Injection Moulding - Numerical Approach
}

\author{
Damir Godec*, Vladimir Brnadić, Tomislav Breški
}

\begin{abstract}
Computer simulation of injection moulding process is a powerful tool for optimisation of moulded part geometry, mould design and processing parameters. One of the most frequent faults of the injection moulded parts is their warpage, which is a result of uneven cooling conditions in the mould cavity as well as after part ejection from the mould and cooling down to the environmental temperature. With computer simulation of the injection moulding process it is possible to predict potential areas of moulded part warpage and to apply the remedies to compensate/minimize the value of the moulded part warpage. The paper presents application of simulation software Moldex 3D in the process of optimising mould design for injection moulding of thermoplastic casing.
\end{abstract}

Keywords: injection moulding; Moldex 3D; mould; numerical simulation; optimisation; warpage

\section{INTRODUCTION}

Injection moulding is one of the most important technologies for polymer processing. It allows high production rate of very complex geometrical shapes of moulded parts from wide range of polymer materials with high dimensional accuracy. Final quality, dimensional and shape accuracy (tolerances) of the moulded parts are the result not only of the applied polymer material and mould design, but also of injection moulding parameters. Injection moulding can be controlled through the number of parameters, with the final goal - production of high-quality moulded parts in the shortest possible injection moulding cycle time.

Modern trends in injection moulding, such as application of polymer materials with specific rheological and thermal properties, complex moulded part designs (e.g. thin walls), application of moulds with large number of mould cavities on one side, and requirements of higher quality of the moulded parts (e.g. dimensional and shape accuracy) on the other side, require comprehensive knowledge about polymer materials, mould design and influence of the most important processing parameters on the final moulded part quality. In the recent years numerical simulation of injection moulding became an essential part of the mould design process. It allows mould designers, as well as processors, to predict the occurrences in the mould cavity during all injection moulding phases. It also enables the prediction of the quality of the moulded part, and thus optimisation of the mould design in the early phase. One of the most frequent defects on injection moulded parts is the warpage after ejection from the mould cavity as a result of uneven shrinkage of the polymer melt during solidification. It occurs because of uneven wall thickness of the moulded part and/or uneven cooling of the polymer melt in the mould cavity. [1-4]

The paper presents application of simulation software Moldex 3D in the process of optimisation of the mould design for injection moulding of thermoplastic casing, in order to minimize the value of the moulded part warpage.

\section{MOULDED PART WARPAGE}

The quality of injection moulded plastic parts is the result of a complex combination of many factors which include used materials, processing parameters, and part and mould designs which can affect the shrinkage behaviour of the injection moulded part. Shrinkage is defined as the reduction in the size of the part as compared to the size of the mould. Material properties, part design, mould design, and processing conditions are influencing factors for nonuniform part shrinkage. Uneven shrinkage will cause moulded part deformation and change in shape, known as warpage. Warpage is a result of formation of stress in the moulded part structure, mainly due to two causes: thermal and pressure induced stresses [1]. In this paper thermal induced warpage will be analysed.

The residual thermal stresses arise when a piece of material is cooled inhomogeneously and when the cooling furthermore causes it to stiffen. When the surface cools, surface layer is free to contract and does not contribute to stress formation. In the following time steps, as the core layer contracts, the solidified surface layer hinders contraction of the core, which ultimately results in a parabolic stress profile with compressive stresses in the surface and tensile stresses in the core [2], as shown in Fig. 1.
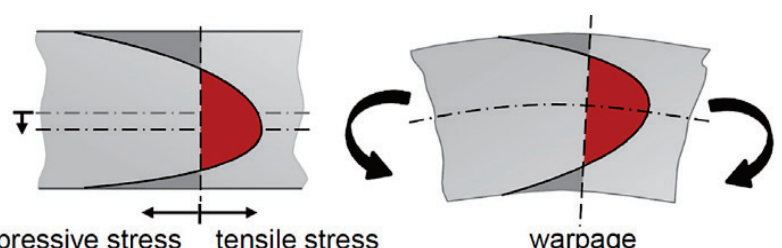

compressive stress tensile stress warpage

Figure 1 Thermal residual stress distribution across moulded part wall thickness [2]

Moulded part geometry (wall thickness, ribs, corners, etc.) in synergy with mould temperature regulation can have significant and complex influence on the moulded part shrinkage and the resulting warpage. One typical example is uneven shrinkage and warpage of the moulded part due to uneven cooling behaviour in the corners (Fig. 2). During the cooling process in injection moulding, heat fluxes in the 
mould are lower in inner corners and then the cooling becomes asymmetric (Fig. 2B).

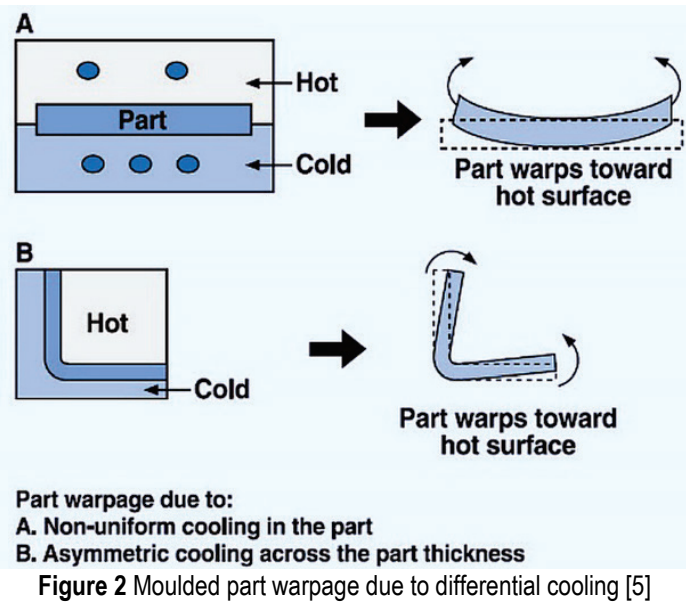

Cooling channel placement within the mould also determines cooling efficiency and uniformity. Positioning the channels too close to the cavity surface can cause cold spots and uneven cooling. If they are too far away, cooling becomes more uniform but less efficient. As shown in Fig. 3, uneven distances to the cavity surface lead to an uneven heat exchange. [6]

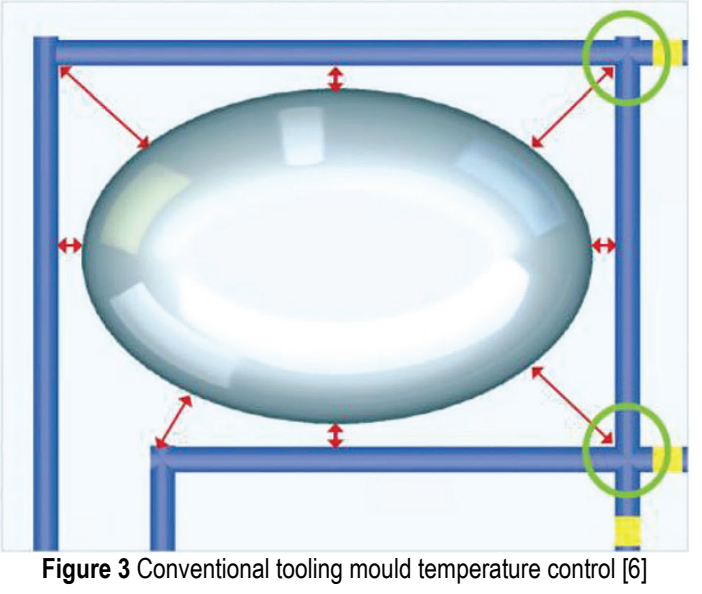

For amorphous polymers, one of the most influencing factors in part shrinkage is the mould temperature. With lower mould temperatures, faster cooling rates are achieved which results in less time for macromolecular chain orientation, thus decreasing shrinkage. With mould temperature increase, cooling rate is decreased, which results in higher degree of macromolecular chain orientation, which consequently increases material shrinkage.

For semi-crystalline polymers, one of the most influencing factors in part shrinkage is achieved material crystallinity. With lower mould temperatures and high cooling rates, crystallization is hindered which results in lower part shrinkage. Likewise, with mould temperature increase, macromolecular chains have more time to crystallize which results in increased part shrinkage. [7]
In order to optimise injection moulding process and moulded part properties, many toolmakers apply new strategies in mould design and production. Most of them are focused on optimisation of heat exchange in the moulds in order to reduce injection moulding cycle time as well as to improve moulded part quality and to extend the mould lifetime. Additive manufacturing (AM) tooling with conformal cooling is the possible answer to those requirements. [8]

\section{CONFORMAL COOLING}

Cooling efficiency is particularly dependent on cooling channel characteristics such as proximity to the mould cavity, cross-sectional area, length, route and surface roughness. However, the design of conventional drilled cooling channels in injection moulds is limited by traditional manufacturing constraints such as the linear nature of the drilling process, which restricts the ability to conform the channel to the contour of the mould cavity (Fig. 4). Variation in the proximity of cooling channels to the mould cavity results in uneven heat dissipation, leading to: increased cycle time, part warping and sink marks, internal part stresses, and reduced tool life due to thermal stresses. $[6,8,9]$

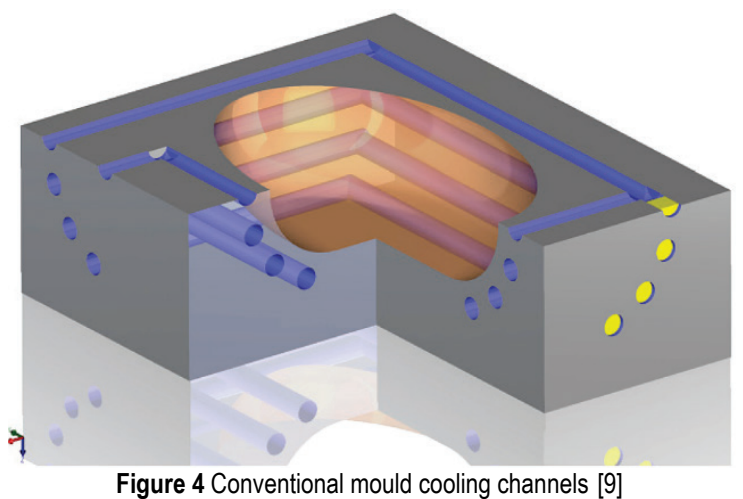

AM mould inserts can be built with internal cooling channels that follow the contour of the cavity beneath the surface (Fig. 5).

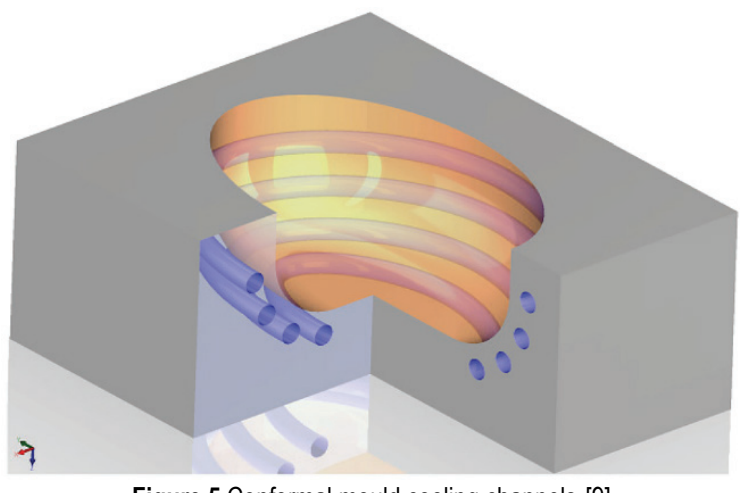

Figure 5 Conformal mould cooling channels [9]

Because the form of the channels follows the contour of the mould, the method is called conformal cooling. Due to the more intensive heat exchange, the productivity of a 
polymer injection mould can be increased significantly. Conformal cooling channels, applied with no numerical simulation will, generally, result in about a $10 \%$ cycle time improvement. On the other hand, conformal cooling channels, applied with numerical simulation and analysis will, generally, result in cycle time improvements from 20 to $40 \%$. $[6,8,9]$

The use of conformal cooling channels also optimizes the moulding process by providing a constant temperature gradient and thus more even heat distribution throughout the mould. When plastic cools evenly, internal stress is minimized. This results in a higher quality part with less warping or sink marks. The more controlled cooling offered by conformal cooling channels allows you to precisely control how the plastic solidifies in the mould and, therefore, to minimize part distortion and shrinkage. [8]

The ultimate objective in optimisation of the injection moulding cycle time and moulded part quality is the creation of a mould temperature control system, which enables a constant and adapted temperature level for the polymer material, during the running injection moulding process on each point of the moulding surface. In order to achieve this result, when applying conformal cooling, appropriate coolant flow strategy and cooling channel shape have to be determined.

When designing conformal cooling channels, it's always recommended to use an injection moulding simulation software package (CAE) in order to identify different temperature zones within a mould so that the conformal cooling channels can be separated and optimised within each region. When designing conformal cooling channels, the first decision that needs to be made is which coolant flow strategy to use. There are three different strategies: zigzag pattern, parallel channel design and spiral channel design (Fig. 6). [8]
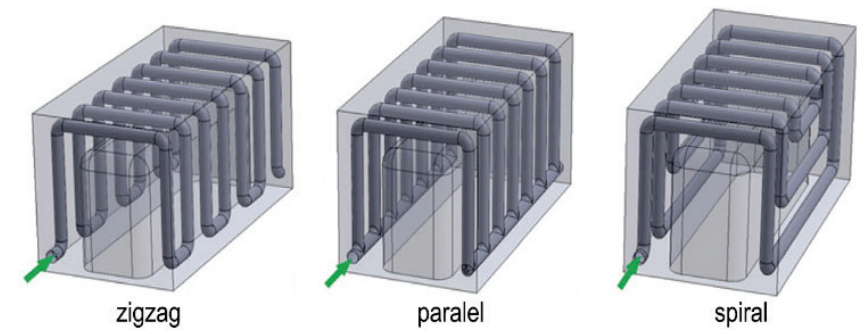

Figure 6 Types of conformal cooling strategies [8]

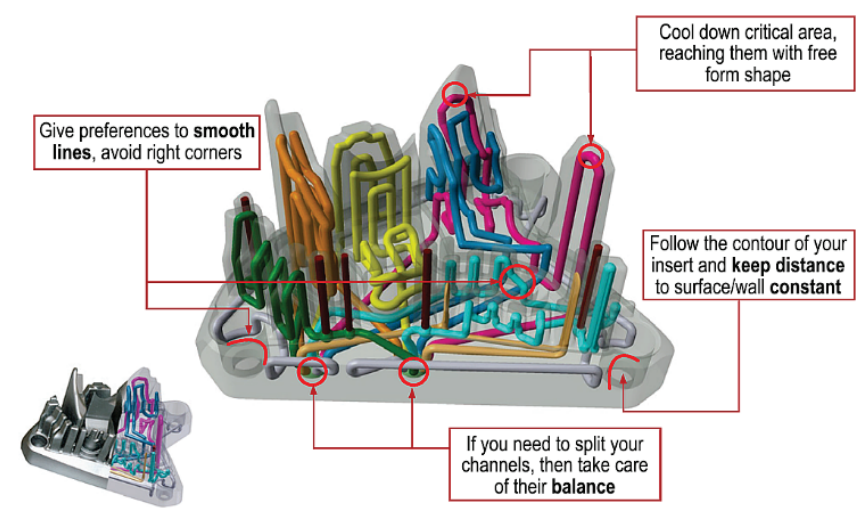

Figure 7 Conformal cooling of complex mould insert [10]
On complex tools, one can sometimes combine cooling strategies where, for example, part of the tool uses a zigzag type strategy, while the rest of the tool employs a parallel strategy. For very complex mould inserts specific rules have to be employed for optimal cooling (Fig. 7).

\section{NUMERICAL INJECTION MOULDING SIMULATION}

Software for numerical simulation of injection moulding have been developed to simulate the processing of the polymer from a melt phase at the start of injection to a solidified product at the time of ejection. The aim of these applications is to predict and understand the causes of shrinkage and warpage which might occur during production.

In the majority of applications for numerical simulation the injection moulding process is divided into 4 steps (Fig. 8). During the simulation of the cavity filling and melt compression phase, the flow of the thermoplastic melt through the runner system and mould cavity(ies) is analysed. During the phase of packing pressure, the occurrences in the mould cavity are analysed, which include additional material flow into the cavity in order to compensate potential part shrinkage. At the end of the packing phase, the cavity needs to be $100 \%$ filled. [11] The analysis of the moulded part solidification consists of determination of the moulded part cooling time and optimal parameters of the mould temperature regulation system. It is also possible to get insight into the temperature field of the mould which substantially determines the quality of the moulded part.

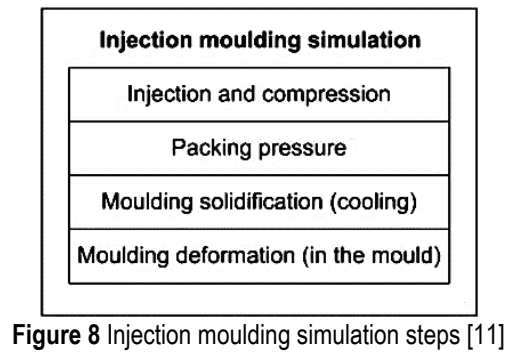

During injection moulding simulation, it is important to decide whether the transient temperature effects are taken into consideration, since transient cooling simulations are more time consuming, but provide more insight in time dependent temperature distributions throughout multiple injection moulding cycles. Within certain amount of time, mould reaches its thermal steady-state, so no cycle temperature variations are present, and the temperature distributions are identical to the values calculated in steadystate cooling simulations.

\section{NUMERICAL OPTIMISATION OF MOULD FOR CASING}

In this chapter various mould configurations are observed with respect to overall part warpage and functional surfaces flatness measurement. Mould configurations are varied by changing the runner system type (cold runner system vs. hot runner system) and cooling system configuration (conventionally drilled cooling channels vs. 
AM produced conformal cooling channels). In all simulations, selected material was widely available ABS Terluran $867 \mathrm{M}$ from BASF which is being processed at melt temperature of $250{ }^{\circ} \mathrm{C}$ and mould temperature of $80{ }^{\circ} \mathrm{C}$. Polymer part being produced is a generic soap case with average thickness of $2 \mathrm{~mm}$ (Fig. 9)

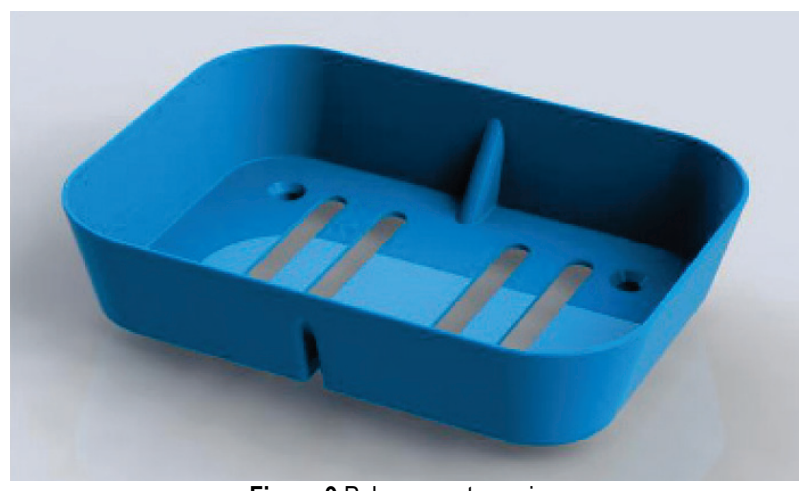

Figure 9 Polymer part - casing

Prior to all actions regarding mould optimisation, overall part thickness needs to be evaluated. Potential part deformations can occur in areas with increased thickness, so these areas need to be carefully inspected during result assessment. Filleted features can lead to thinner part regions if fillet values are not identical on the inner and outer surfaces of part (Fig. 10). These areas lead to increased flow resistance which can lead to hindered pressure distribution during packing phase, which can ultimately lead to increased part warpage [12].

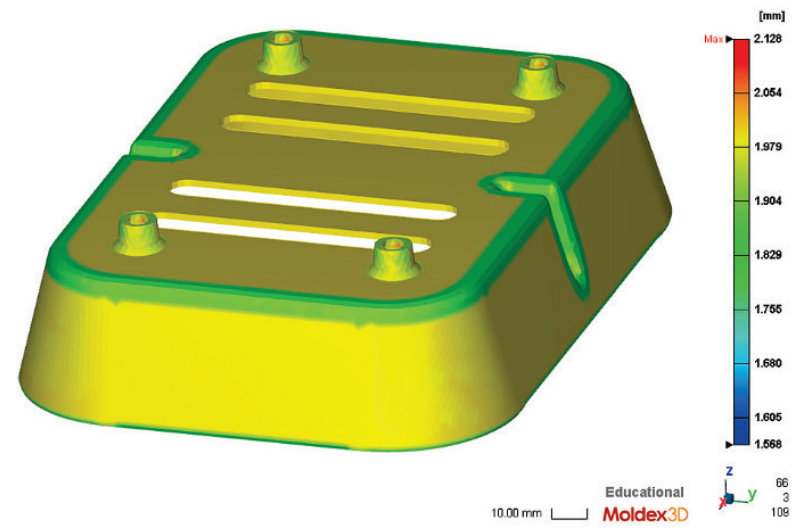

Figure 10 Moulded part thickness distribution

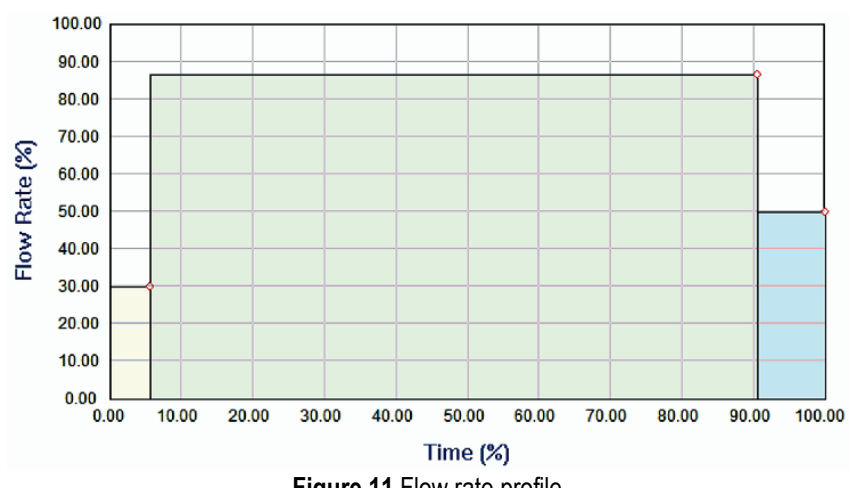

Figure 11 Flow rate profile
Since processing parameters can also influence the part warpage, in all numerical simulations initial processing parameters are defined identically. Maximum machine injection pressure is $155 \mathrm{MPa}$, while flow rate profiles and packing pressure profiles are defined as shown in Fig. 11 and Fig. 12.

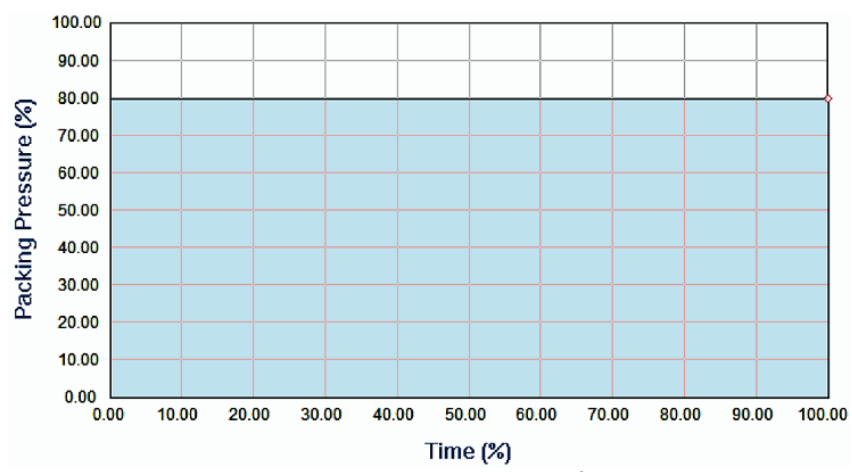

Figure 12 Packing pressure profile

\subsection{Cold Runner System with Conventionally Drilled Cooling Channels}

The least complex mould configuration consists of cold runner system which ends with cold edge gate, while cooling channels are conventionally drilled (Fig. 13).

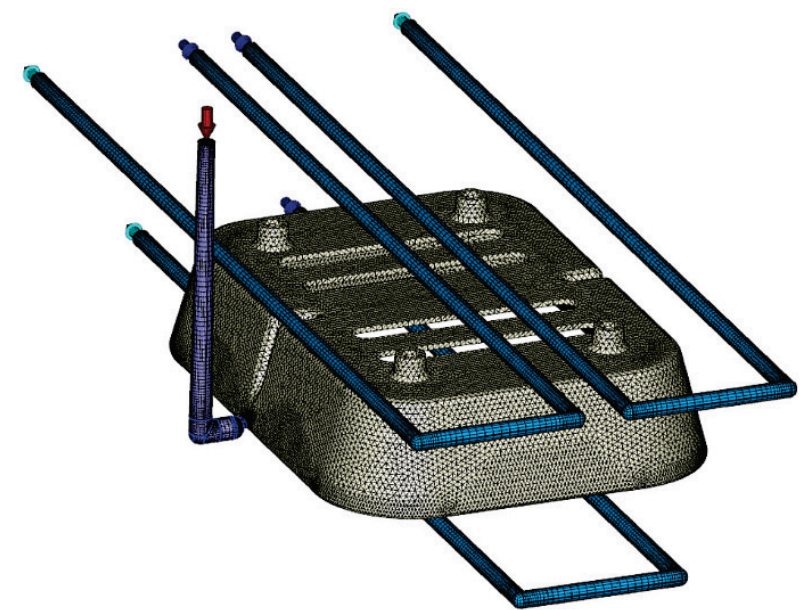

Figure 13 Simulation model with cold runner system and conventionally drilled cooling channels

Since in this mould configuration cavity is filled from one side of the cavity, due to uneven distances of cavity surfaces from cavity inlet point, uneven melt flow front is formed (Fig. 14).

By inspecting the packing pressure distribution (Fig. 15), potential warpage influence is observed. Areas which are farthest from the gate aren't subjected to packing pressure at all, which results in increased shrinkage in these areas. Packing pressure distribution is limited by gate dimensions and its freezing time, since after the gate is frozen, no pressure from injection moulding machine can influence the packing phenomena in areas which are farthest from the cavity gate. In order to improve packing pressure distribution, gate dimensions need to be increased so that the 
gate freeze occurs later, during the packing phase. This makes packing phase longer, and more influential on the total part warpage. Gate freeze time can also be postponed with melt temperature increase and mould temperature increase. [12]

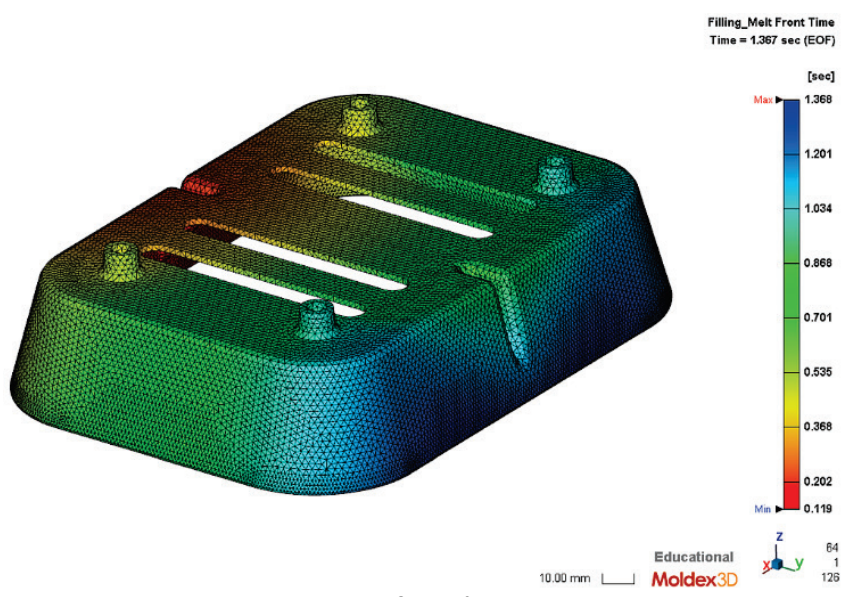

Figure 14 Cavity filling time

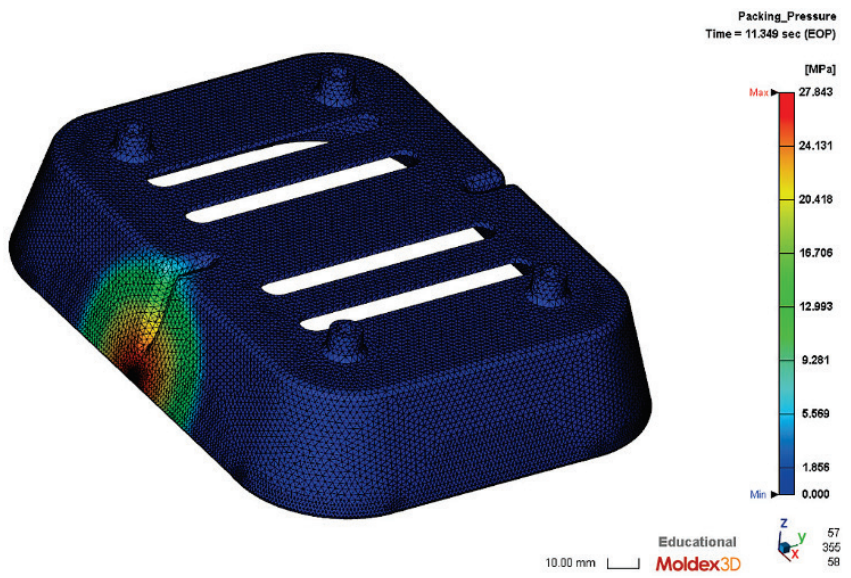

Figure 15 Packing pressure distribution

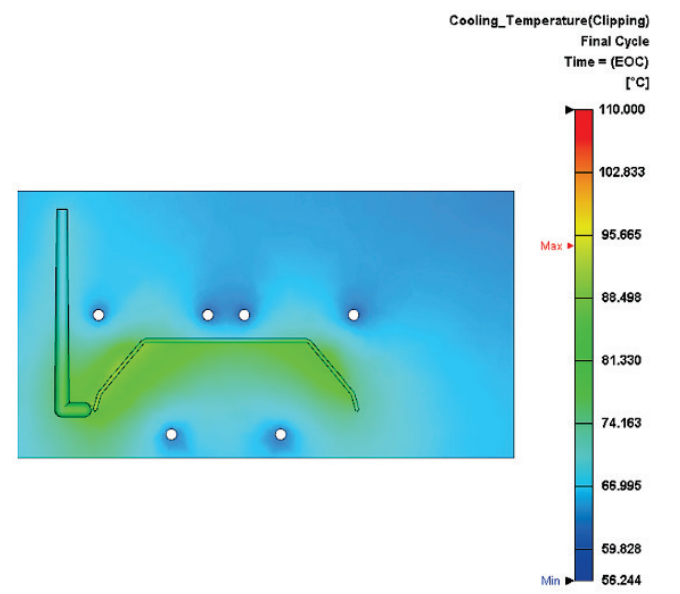

Figure 16 Mould temperature distribution (conventional cooling channels)

Since cooling channels are conventionally drilled, they can't be positioned in optimal locations inside the mould, therefore substantial temperature gradients are visible (Fig. 16) due to sub-optimal cooling efficiency (Fig. 17). In certain areas of the cavity, maximum core to cavity temperature difference is estimated as $20.8{ }^{\circ} \mathrm{C}$ (Fig. 16) which results in increased part warpage.

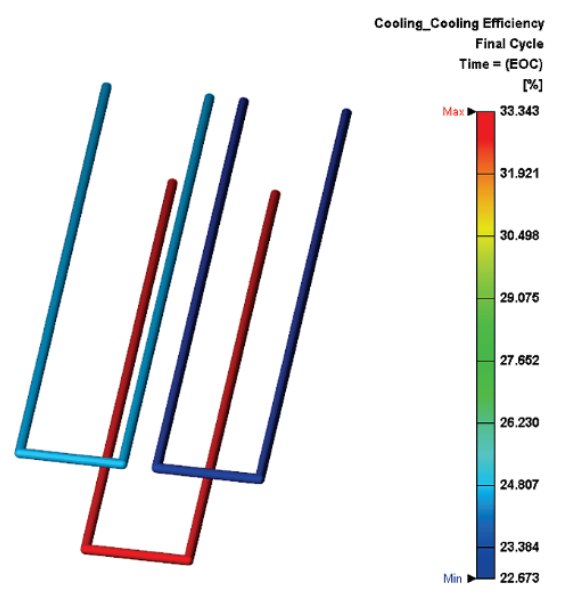

Figure 17 Cooling efficiency of conventionally drilled cooling channels

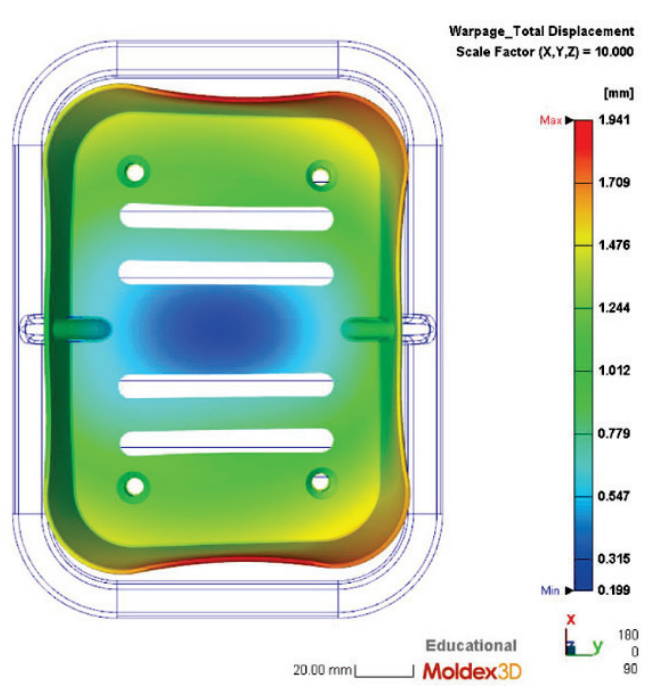

Figure 18 Warpage distribution with conventional cooling

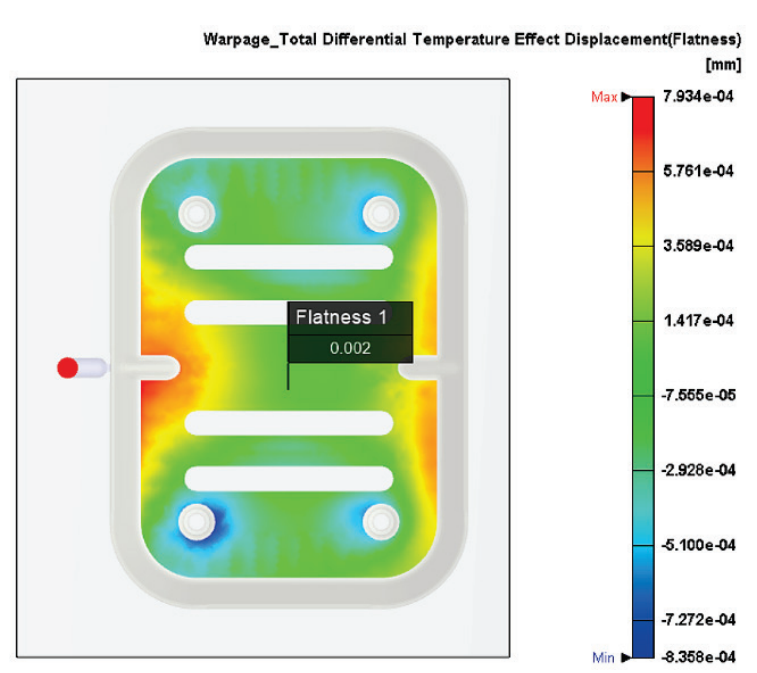

Figure 19 Top surface warpage due to differential temperature effect

By inspecting the final part warpage, it is visible that the areas which are farther away from the gate are more warped 
(Fig. 18). It is important to emphasize that the warpage distribution is scaled by the factor of 10 , which allows for better comprehension of warpage phenomenon.

Flatness of the top surface has been inspected (Fig. 19, Fig. 20) and the results show that the top surface is warped, but the most influential source of warpage comes from differential shrinkage.

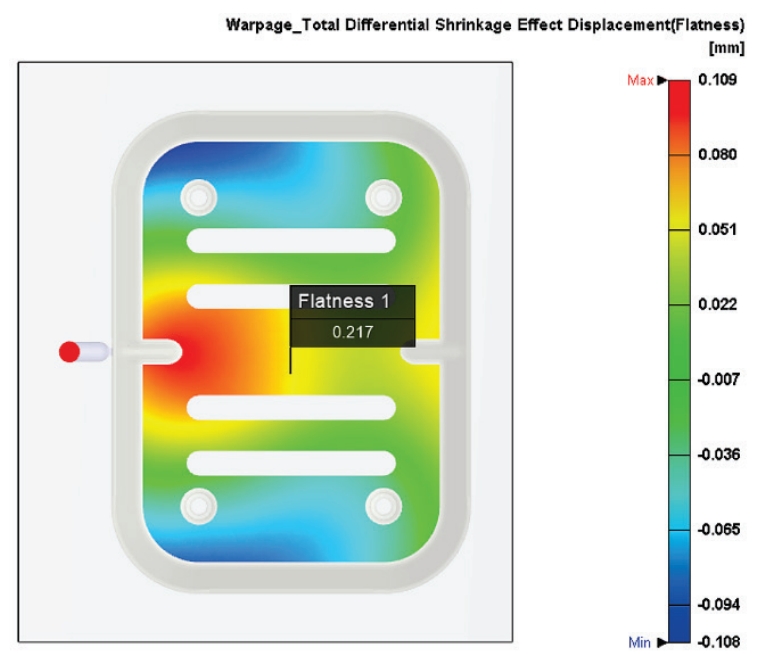

Figure 20 Top surface warpage due to differential shrinkage effect

\subsection{Cold Runner System with Conformal Cooling Channels}

By utilising the possibilities of AM, conformal cooling channels can be produced in order to improve thermal characteristics of the mould. In this mould configuration, both core and cavity are designed with inclusion of conformal cooling channels which are evenly spaced in the mould cavity (Fig. 21). It is important to state that the material characteristics of additively manufactured mould inserts are not identical to conventionally manufactured due to the nature of the additive manufacturing process (e.g. hindered thermal properties due to internal voids), but for this example identical material characteristics are considered.

In this configuration, heat can be more evenly extracted across all surfaces of the cavity, so better temperature distributions are achieved (Fig. 22).

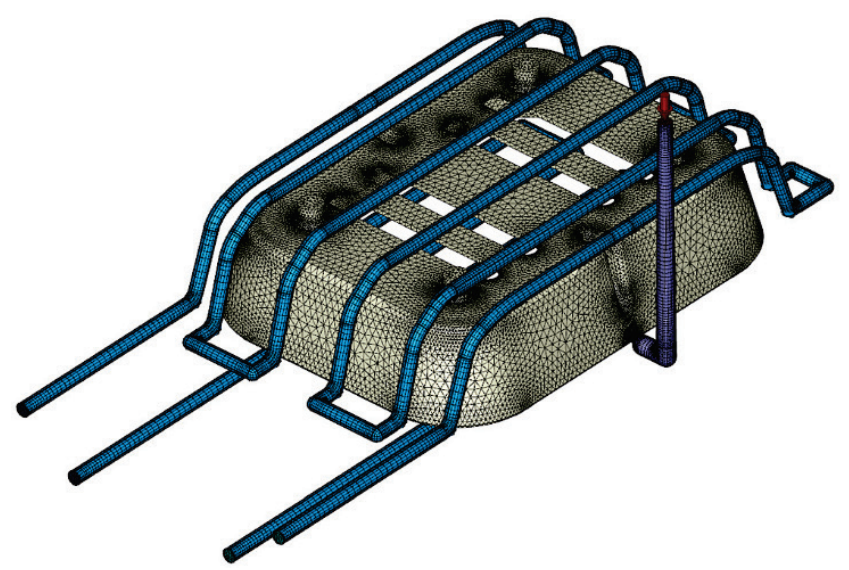

Figure 21 Simulation model with cold runner system and conformal cooling channels

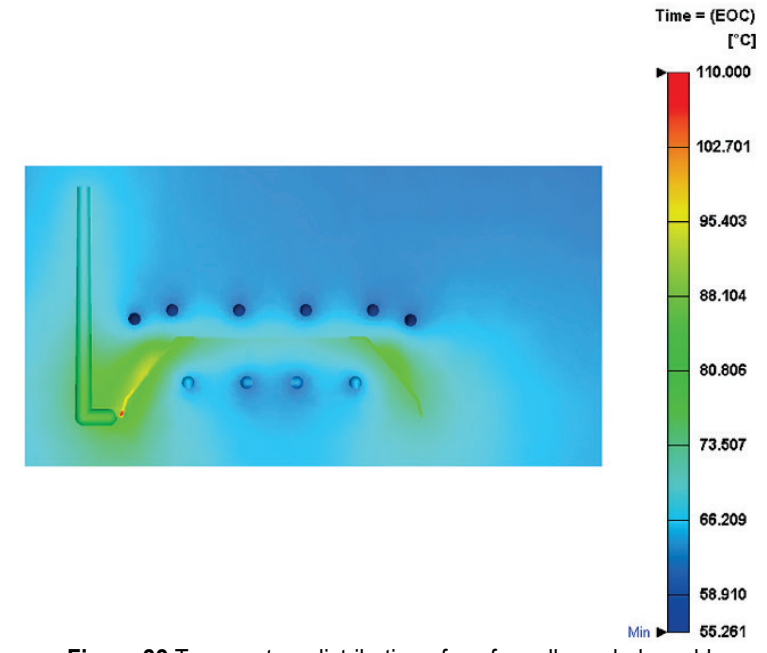

Figure 22 Temperature distribution of conformally cooled mould

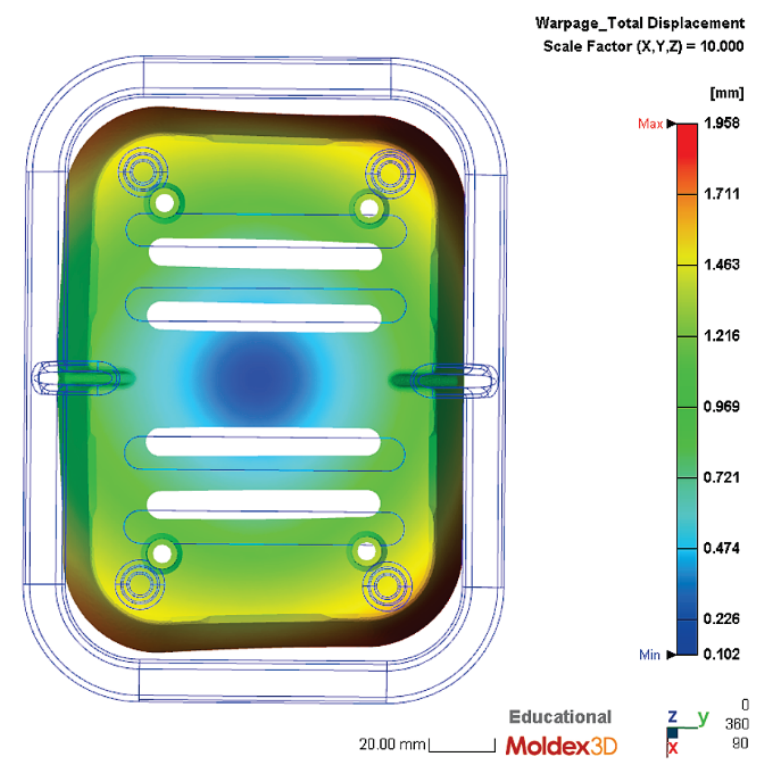

Figure 23 Warpage distribution with conformal cooling

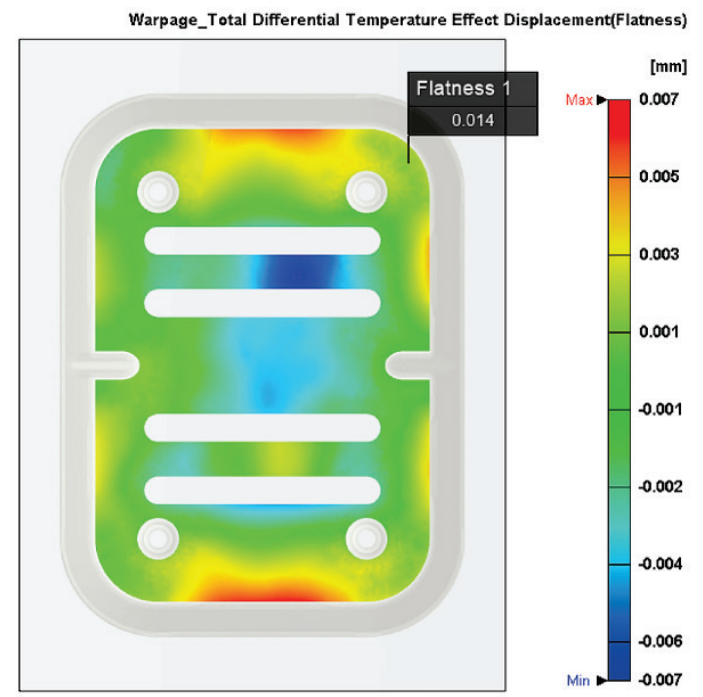

Figure 24 Top surface warpage due to differential temperature effect 
Still, due to the runner system configuration, most of the warpage is related to differential shrinkage which leads to only slight improvement regarding total part warpage (Fig. 23).

Flatness measurement shows that the conformal cooling channels have improved the surface flatness regarding differential shrinkage effect. The warpage has worsened a bit due to differential temperature, but the temperature caused warpage value is $0,014 \mathrm{~mm}$ which is acceptable result (Fig. 24 and Fig. 25).

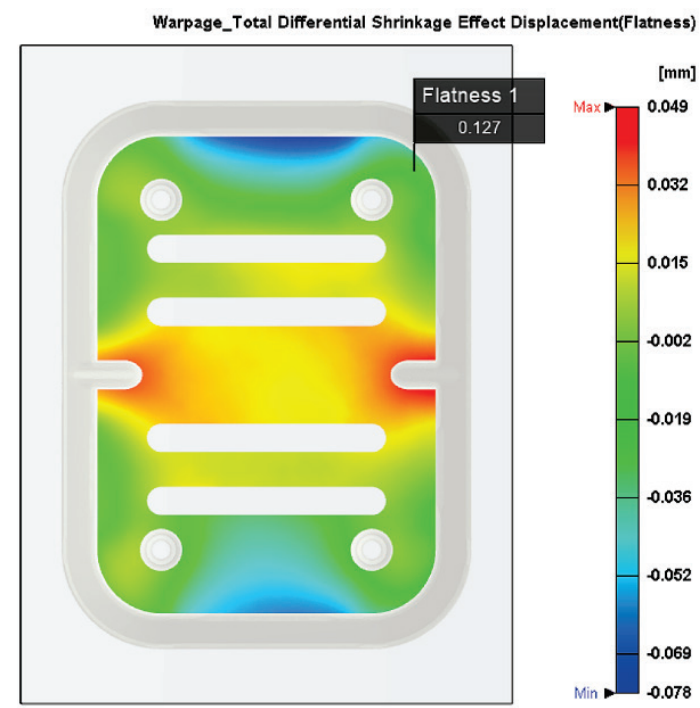

Figure 25 Top surface warpage due to differential shrinkage effect

\subsection{Hot Runner System with Conformal Cooling Channels}

In order to reduce the differential shrinkage problem, gate location should be relocated to the optimal position based on better melt flow distances inside the cavity. By placing the gate location in the middle of the top part surface (Fig. 26), during fill phase polymer melt travels the least through the cavity. Moreover, by utilising hot runner system, packing pressure distribution is more even which results in additional warpage reduction.

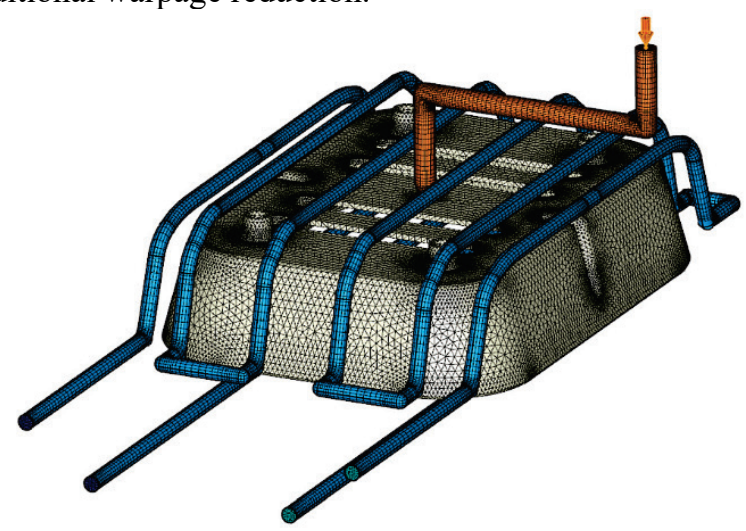

Figure 26 Simulation model with hot runner system and conformal cooling channels

Temperature distribution (Fig. 27) shows that there is no substantial temperature difference between core and cavity.

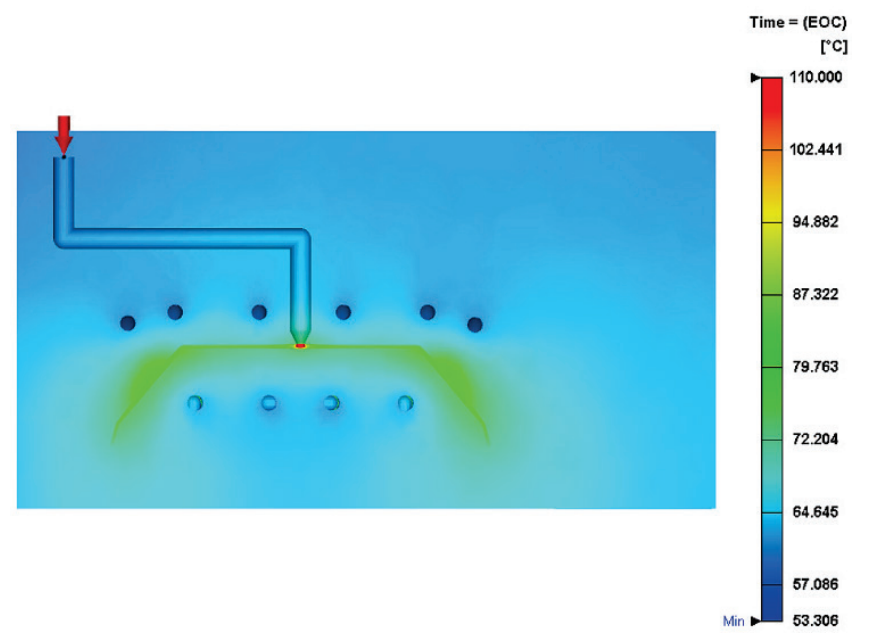

Figure 27 Temperature distribution of conformally cooled mould with optimal gate placement

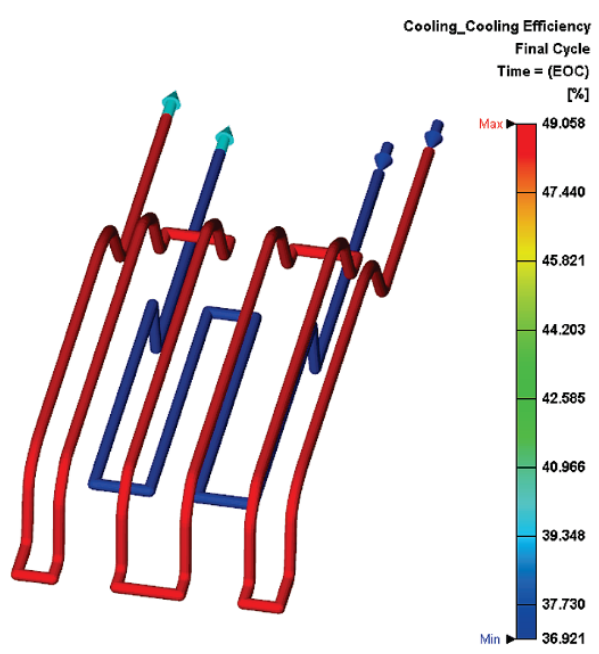

Figure 28 Conformal cooling channels efficiency

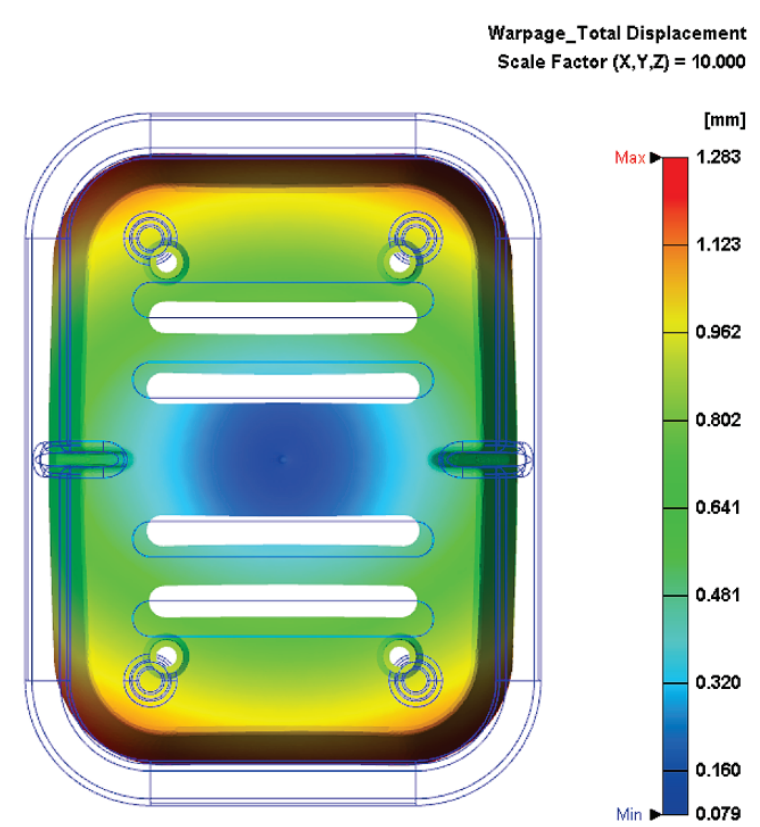

Figure 29 Warpage distribution with hot runners and conformal cooling 
Conformal cooling channels have improved efficiency due to optimised placements related to mould cavity surface (Fig. 28).

By inspecting the warpage, it is visible that the warpage distribution is symmetrical, which can be compensated with anisotropic part scaling prior mould design and detailing (Fig. 29).

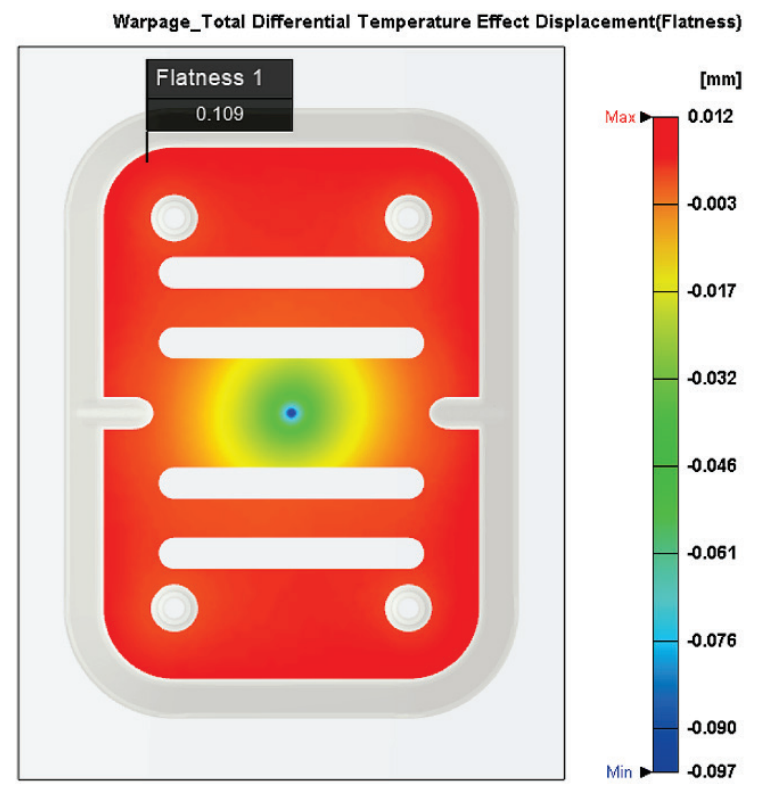

Figure 30 Top surface warpage due to differential temperature effect

Top surface flatness is still sub-optimal, so in order to improve it, further optimisation needs to be done from the processing parameters side. Also, due to increased heating from hot runner system, warpage due to differential temperature effect has substantially increased (Fig. 30, Fig. $31)$.

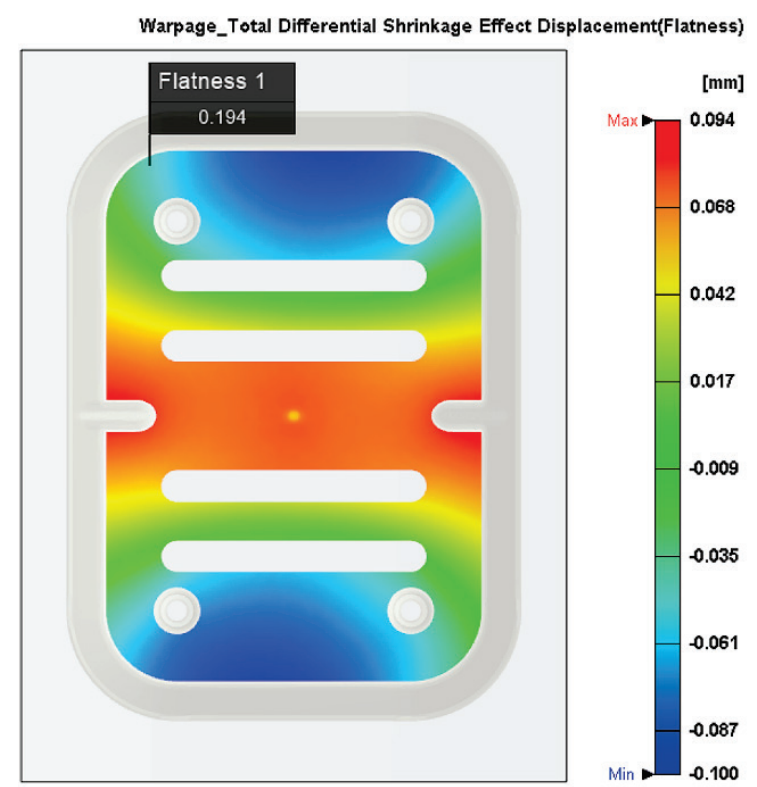

Figure 31 Top surface warpage due to differential temperature effect

\subsection{Results Discussion}

The best results regarding part warpage are achieved with cold runners and conformal cooling (Fig. 32). Top surface flatness which originates from differential temperature effect is the best in the case of cold runners and conventional cooling. Since flatness was measured on the top surface, by placing the hot runner gate at that plane, warpage due to differential temperature effect is the worst in the case of centrally placed hot runner gate and conformal cooling channels. Regarding the differential shrinkage effect, the best results are achieved with cold runners and conformal cooling channels.

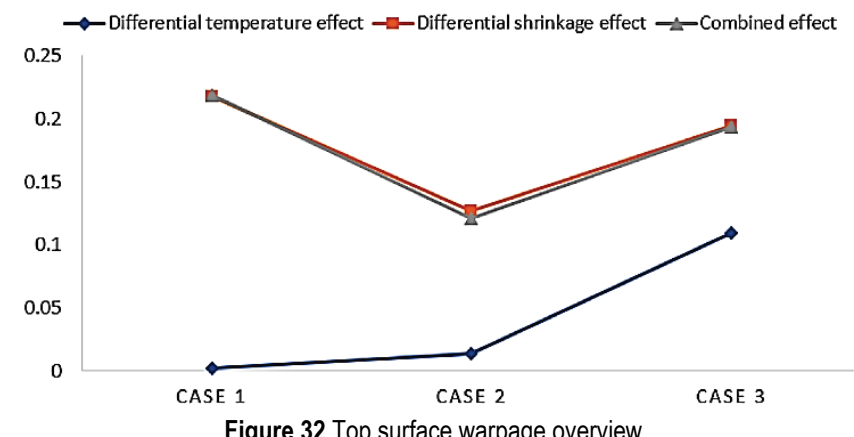

\section{CONCLUSION}

By utilising numerical simulation in mould optimisation, total part warpage was reduced by approximately $28 \%$ in the case of application of cold runner system and conformal cooling channels. Since all optimisation tasks were done using numerical simulations, additional tooling costs are avoided. In low to medium scale production, tooling costs have a substantial impact on total production cost, so appropriate mould configurations need to be taken into consideration. Moulds with cold runner systems and conventionally drilled cooling channels are the cheapest mould configurations, but due to sub-optimal gate location, packing conditions are not fulfilled through all regions of mould cavity. This leads to differential shrinkage, which results in substantial amount of part warpage. By utilising hot runner system and conformal cooling channels, tooling costs are higher, but total warpage is significantly reduced, and surface flatness improved. Some degree of warpage reduction is possible with further optimisation of processing parameters.

\section{Acknowledgements}

Authors would like to express their gratitude to company eCon Engineering Kft. for their support related to numerical simulations and granting access to Moldex3D software.

\section{Notice}

The paper will be presented at MOTSP $2021-12^{\text {th }}$ International Conference Management of Technology - Step to Sustainable Production, which will take place in 
Poreč/Porenzo, Istria (Croatia), on September 8-10, 2021. The paper will not be published anywhere else.

\section{REFERENCES}

[1] Demirci, U. \& Altan, M. (2020). Warpage Analysis of Injection Molded Thin-Walled Chassis Part by RSM and FEM. Journal of Advances in Manufacturing Engineering, 1(2), 63-70.

[2] Kozlovski, T. \& Bonten, C. (2019). Shrinkage, warpage and residual stresses of injection molded parts. AIP Conference Processings 2055, 07003. https://doi.org/10.1063/1.5084847

[3] Dang, X. P. (2014). General frameworks for optimization of plastic injection molding process parameters. Simulation and Modelling Practice and Theory, 41, 15-26. https://doi.org/10.1016/j.simpat.2013.11.003

[4] Nian, S.-C., Wub; C.-Y. \& Huang, M.-S. (2014). Warpage control of thin-walled injection molding using local mold temperatures. International Communications in Heat and Mass Transfer, 61(2015), 102-110. https://doi.org/10.1016/j.icheatmasstransfer.2014.12.008

[5] N. A. (2005). Design Guide - Performance and Value with Engineering Plastics, DSM Engineering Plastics, USA

[6] Tuteski, O. \& Kočov, A. (2018). Conformal cooling channels in injection molding tools - design considerations. International Scientific Journal "Machines. Technologies. Materials", 12(11), 445-448.

[7] Rizvi, S. J. A. (2017). Effect of injection molding parameters on crystallinity and mechanical properties of isotactic polypropylene. International Journal of Plastics Technology, 21(2), 404-426. https://doi.org/10.1007/s12588-017-9194-3

[8] Diegel, O., Nordin, A., \& Motte, D. (2020). A Practical Guide to Design for Additive Manufacturing. Singapore, Singapore: Springer Nature. https://doi.org/10.1007/978-981-13-8281-9

[9] Mayer, S. \& Niavas, A. (2009). Conformal cooling: Why use it now? https://www.plasticstoday.com/injection-molding/ conformal-cooling-why-use-it-now (Accessed 15.03.2021)

[10] N. A. (2015). Shaping the future of die and moulds: EOS tooling, Meeting SHL-EOS. EOS GmbH, Krailing, Germany.

[11] Godec, D., Šercer, M., \& Rujnić-Sokele, M. (2007). Computer Simulation of Thin-wall Injection Moulding of Thermoplastics. CIM 2007, The $11^{\text {th }}$ International Scientific Conference on Production Engineering, Conference Proceedings, Croatian Association of Production Engineering, Biograd, 1317.06.2007, 133-140.

[12] Wang, M.-L., Chang, R.-Y., \& Hsu, C.-H. (David) (2018). Molding Simulation: Theory and Practice. Carl Hanser Verlag, Munich. https://doi.org/10.3139/9781569906200.fm

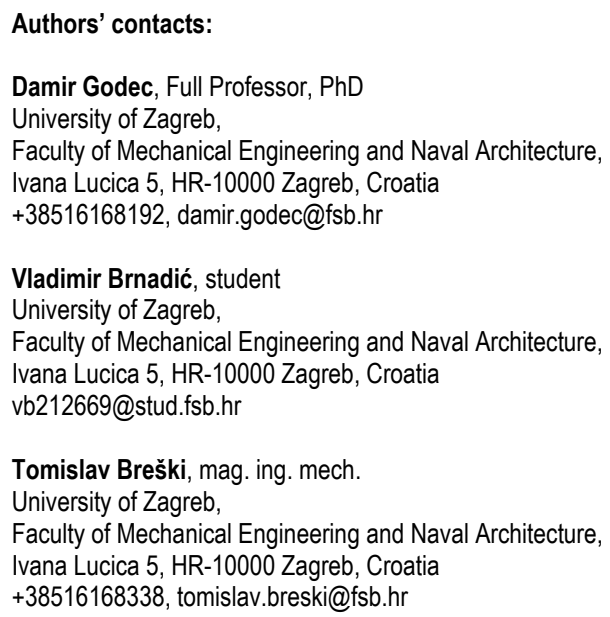

